(C) Elsevier Sequoia S.A., Lausanne - Printed in the Netherlands

\title{
MECHANISMS OF FORMATION OF POLYMERIC TRANSFER FILMS*
}

\author{
S. H. RHEE and K. C. LUDEMA
}

Department of Mechanical Engineering, The University of Michigan, Ann Arbor, Michigan (U.S.A.)

(Received July 5, 1977)

\section{Summary}

The role of the transfer film in reducing wear of polymers is discussed. It is shown that the transfer film forms more readily on roughened surfaces and that it can exist in a solid state and in a low viscosity or fluid state. Each state controls friction and wear of the polymer in a different way.

\section{Introduction}

When polymeric solids slide against other solids such as steel there appears to be no way to predict either the friction of the system or the wear life of the polymer from handbook data. Friction and wear vary over wide ranges when sliding speed, applied load and system temperature are varied. Neither have thermal analyses of the sliding system produced satisfying results, partly because of the difficulty in measuring temperatures in the sliding in terface.

However, there is some progress in these studies. Dowson [1] reports a thermal analysis of sliding by extrapolation from temperatures measured by thermocouple in several locations within the metal counterface. Lancaster [2] reports wear at low rubbing severity and attributes it to a fatigue mechanism. Finally, a number of authors of both research papers and test reports note that in some cases a polymeric film is transferred and remains firmly attached to the metal counterface, with the apparent effect of reducing wear.

This paper reports the results of some work to measure the properties of the transfer film and proposes a model for transfer film formation and behavior. The research reported consisted in the measurement of friction and wear rate over a wide range of load and speed together with measurements of temperatures in the vicinity of the sliding interface. Transfer films were

*Paper presented at the International Conference on the Wear of Materials, St. Louis, Mo., U.S.A., April $26 \cdot 28,1977$. 
observed visually during the tests but the thickness and dynamic mechanical properties were not determined directly.

In view of the strong influence of the controllable variables in friction and wear the experimental apparatus and materials will be described in some detail, although this has been done in a previous paper [3]. In the tests the severity of rubbing covered a range from well below conditions for severe wear to the conditions for severe wear. Severity of rubbing is defined in terms of the product $\mu W V$ where $\mu$ is the coefficient of friction, $W$ is the applied load and $V$ is the sliding speed. The product $\mu W V$ is taken as the input mechanical energy to the sliding interface.

\section{Experimental}

\section{Materials}

Commercially available nylon 66, poly(oxymethylene) (DuPont's Delrin) and PTFE-dispersed poly(oxymethylene) (DuPont's Delrin AF) were purchased from Cadillac Plastics, Detroit, Michigan, in the form of extruded rods of $12.7 \mathrm{~mm}(1 / 2 \mathrm{in})$ diameter. They were cut into 1 in long cylinders and the rubbing side of the cylindrical specimens was reduced to $6.35 \mathrm{~mm}$ (1/4 in) diameter.

\section{Apparatus}

The experimental system used in this work is shown in Fig. 1.

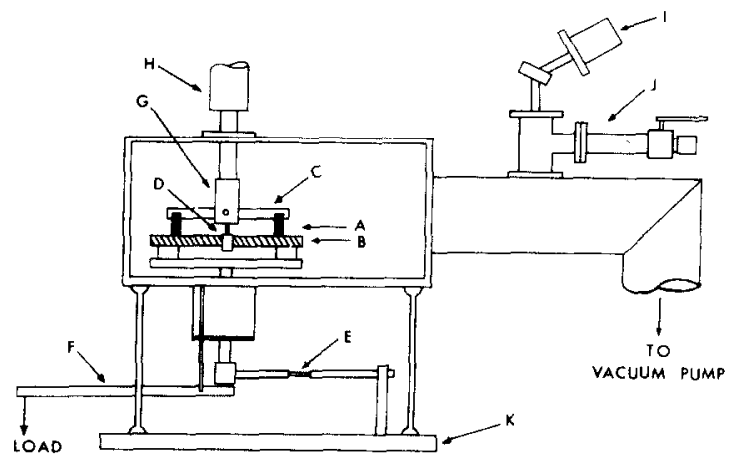

Fig. 1. Experimental test apparatus: A, polymer specimen; B, countersurface; $C$, pivoted specimen holding bar; D, LVDT wear transducer; $E$, friction force constraint arm; F, loading arm; $G$, input shaft; $H$, drill press spindle; I, mass spectrometer; J, solid sample probe; $K$, drill press support.

Two polymer specimens are held opposite to each other on ends of a bar (C) pivoted at its center; the center-to-specimen distance is $98 \mathrm{~mm}$. The resulting contacting geometry is a dual-pin-on-disc configuration. One of the countersurfaces is a disc of $440 \mathrm{C}$ stainless steel $254 \mathrm{~mm}$ in diameter and 
$25.4 \mathrm{~mm}$ thick, finished to $0.254 \mu \mathrm{m}(10 \mu$ in $)$ surface finish or better. The other countersurface is a disc of quartz $12.7 \mathrm{~mm}(1 / 2$ in) thick.

The friction force is measured by a strain gauge attached on a constraint arm (E) which limits rotation of the countersurface. The normal load is provided by pressing upward on the lower disc shaft and by limiting the vertical motion of the upper input shaft. The sliding system is enclosed in a vacuum chamber and a mass spectrometer analyzing tube is connected to the vacuum chamber. A vacuum of $26.7-40 \mathrm{mPa}\left((2-3) \times 10^{-6} \mathrm{mmHg}\right)$ is easily attained by a combination of a turbomolecular pump and a mechanical forepump. Wear is measured by a linear variable differential transformer (LVDT) (D) located in the center of the countersurface disc. The bulk temperature of the countersurface is measured by an iron-constantan thermocouple, located $3 \mathrm{~mm}$ below the rubbing surface of stainless steel and $2 \mathrm{~mm}$ for quartz.

The mass spectrometer is an AVA-610 $60^{\circ}$ single focusing magnetic sector type manufactured by the Aero-Vac Corporation. A pyrolysis probe $(\mathrm{J})$ is located in the vacuum chamber. Its function is to heat a sample of polymer in a vacuum environment so that the products of thermal decomposition can be analyzed.

\section{Procedure}

The sliding surfaces of polymer specimens were prepared on 600 -grit abrasive paper and cleaned with flowing water, acetone and isopropyl alcohol before being inserted in to the specimen holder. The countersurface of stainless steel was polished with 600 -grit abrasive paper and cleaned with acetone and isopropyl alcohol. The vacuum chamber was then closed and evacuated to a total pressure of $26.7-40 \mathrm{mPa}\left((2-3) \times 10^{-6} \mathrm{mmHg}\right) . A$ certain load and speed were decided for each test, and friction, wear, countersurface temperature and decomposed gases were monitored throughout the test.

Prior to the friction tests a small sample of polymer was heated progressively in the pyrolysis tube and a trace of the evolved gases versus temperature was monitored by the mass spectrometer. Then friction tests were run and the gas analysis was done. Similar gas compositions were taken to mean that the pyrolysis temperature and the friction interface temperature were the same.

\section{Results}

In the experimental program several polymers were made to slide on several substrates, but the most instructive were those done on a 440-C stainless steel plate finished with 600 -grit $\mathrm{Al}_{2} \mathrm{O}_{3}$ abrasive paper, a fine polished quartz plate and a quartz plate finished with 600-grit $\mathrm{Al}_{2} \mathrm{O}_{3}$ abrasive paper. Again tests were run at many combinations of load and speed, but the most illuminating tests were run at a selected combination of 
load and speed, beginning with all components at room temperature. The speed and load were selected such that as the test progressed the rubbing elements heated and severe wear occurred within $600-3600 \mathrm{~s}$ from the beginning of the test. The proper speed and load are different for each polymer and depend to some ex tent on the coefficient of friction of the system. The difficulty in establishing equivalent states may be seen in the data for nylon 11 for two loads, as seen in Table 1.

TABLE 1

Conditions for wear of nylon 11 on a stainless steel plate

\begin{tabular}{llllll}
\hline $\begin{array}{l}\text { Sliding speed } \\
\left(\mathrm{ms}^{-1}\right)\end{array}$ & $\begin{array}{l}\text { Load } \\
(\mathrm{N})\end{array}$ & $\mu$ & $\mu W V$ & $\begin{array}{l}\text { Time to } \\
\text { severe wear } \\
(\mathrm{s})\end{array}$ & $\begin{array}{l}\text { Temperature in steel } \\
\text { substrate at beginning } \\
\text { of severe wear }\left({ }^{\circ} \mathrm{C}\right)\end{array}$ \\
\hline 1.47 & $\begin{array}{l}222 \\
(50)^{\mathrm{a}}\end{array}$ & 0.7 & 228.4 & 300 & 44 \\
1.47 & $\begin{array}{l}444 \\
(100)\end{array}$ & 0.5 & 326.3 & 1020 & 110 \\
\hline
\end{tabular}

${ }^{\mathrm{a}}$ The values in parentheses give the load in pounds force.

The difference between the two tests was that at the low load the transfer film was not properly established and the severe wear debris probably included a large number of "fatigued" fragments. At the higher load the transfer film covered the steel surface more completely and was fully effective in suppressing wear until a high temperature. The latter state was studied and is reported here. The speed and load that produced "equivalent states" in the several polymers tested are shown in Table 2.

Tests were done on quartz, comparing two surface finishes. During the test the wear rate and rate of gas evolution were measured as well. For the smooth quartz the wear rate was high from the start of the test and the volume of gas evolved was always very low. On the abrasive finished quartz there was no wear but a large volume of gas was cvolved from the sliding interface after some time. These observations are consistent with the formation of a stable and highly adherent transfer film on the abrasive finished surface but not on the smooth quartz. Since transfer films are difficult to observe by other than visual means, another test was devised to detect a transfer film. It consisted in measuring the value of $\mu$ of Delrin and then of Delrin AF separately on the smooth and on the abrasive finished quartz. This was followed by sliding Delrin on the "track" of the test with Delrin AF as shown in Table 3. It may be inferred that a transfer film, perhaps predominantly of Teflon, is formed on abrasive finished glass and that the transfer film controls both friction and wear.

Tests were also done to compare quartz and stainless steel, both finished in the same way with abrasive paper. They both produced the same 


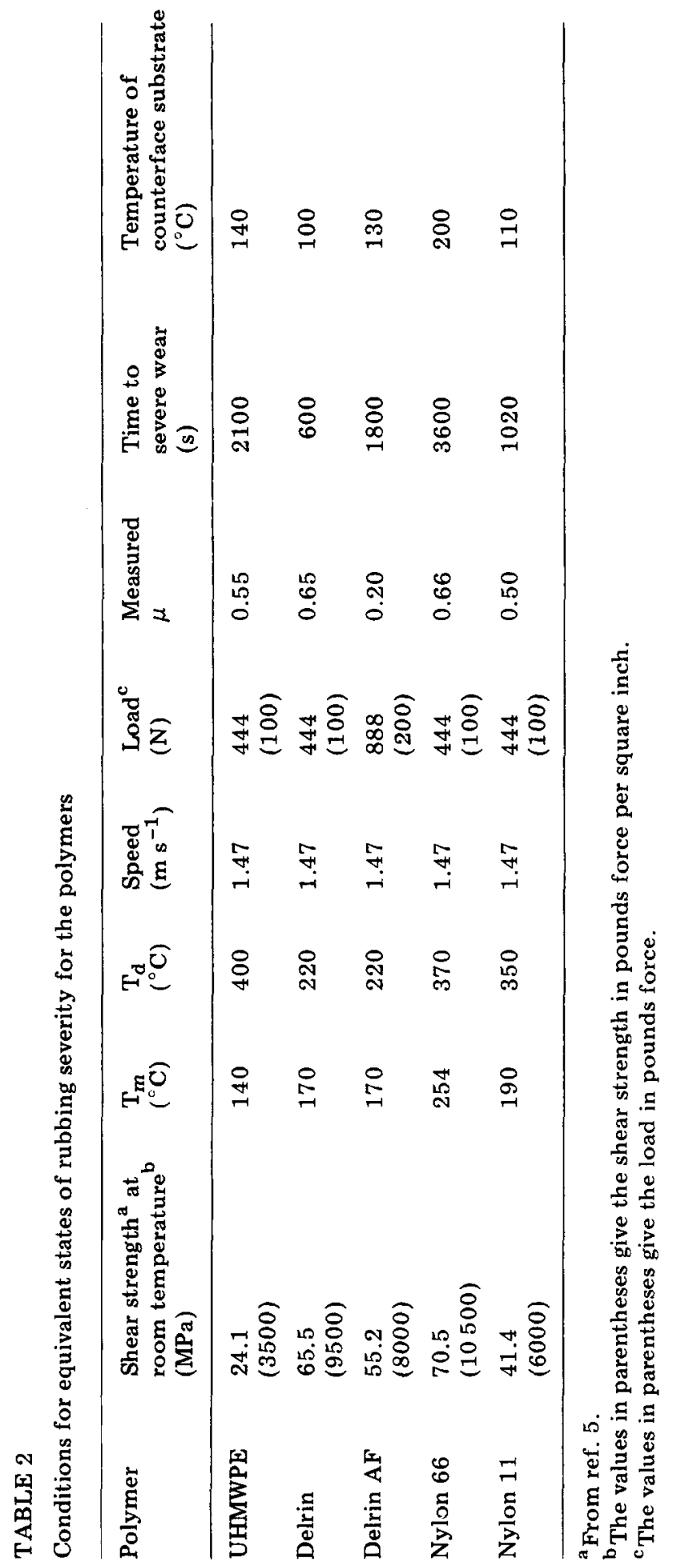


TABLE 3

Coefficient of friction in sequence of tests with Delrin and Delrin AF on quartz

\begin{tabular}{llll}
\hline & $\begin{array}{l}\text { Delrin on } \\
\text { clean glass }\end{array}$ & $\begin{array}{l}\text { Delrin AF on } \\
\text { clean glass }\end{array}$ & $\begin{array}{l}\text { Delrin on track } \\
\text { of Delrin AF }\end{array}$ \\
\hline Smooth quartz & 0.5 & 0.4 & 0.5 \\
Abrasivc finished quartz & 0.5 & 0.2 & 0.2 \\
\hline
\end{tabular}

TABLE 4

Thermal properties of the stainless steel and quartz used in the tests

\begin{tabular}{llllll}
\hline & $1 / K$ & $k / \rho C_{\mathrm{p}}$ & $(1 / k)\left(k / \rho C_{\mathrm{p}}\right)^{1 / 2}$ & $\begin{array}{l}\text { Calculated } \\
\text { ratio }\end{array}$ & $\begin{array}{l}\text { Experimental } \\
\text { ratio }\end{array}$ \\
\hline Stainless steel & 0.04 & $7.1 \times 10^{-3}$ & $0.107 \times 10^{-3}$ & 6 & 6 \\
Quartz & 0.723 & $0.84 \times 10^{-6}$ & $0.663 \times 10^{-3}$ & 1 & 1 \\
\hline
\end{tabular}

results showing, for example, that there are no chemical effects due to the elements in the steel (or quartz) substrates in the formation and degradation of transfer films although the surfaces may be activated because of abrasion. The only difference between the tests using stainless steel and quartz is that the product of applied load and sliding speed for the tests on quartz is $1 / 6$ that on stainless steel to achieve the same results. This experimental finding agrees with expectations gained from calculations using the thermal properties of the two materials as shown in Table 4 .

The calculated quantities are given in the form used in equations for the temperature rise in the polymer (proportional to $1 / k$ ) and the temperature rise in the substrate (proportional to $(1 / k)\left(k / \rho C_{\mathrm{p}}\right)^{1 / 2}$ ) where $k$ is the thermal conductivity, $\rho$ is the density and $C_{\mathrm{p}}$ is the specific heat at constant pressure [4] .

The data for the tests on abrasive finished stainless steel and quartz are shown in Fig. 2 in schematic form. It can be seen that the friction increases at the beginning of the test. The reason is not clear. For very carefully cleaned countersurface material the coefficient of friction begins at a slightly higher value, suggesting that the first few passes of the slider promote desorption of adsorbed gas. Such gases were never detected, possibly because the quantity of gas evolved is too low for the gas analyzer system to detect. There is always some rise in pressure during sliding, however, even in cleaned and previously degassed counterface surfaces. The largest change in friction with time may be due to the formation of the transfer film. It is interesting that the value of $\mu$ does not change significantly at a later time when the temperatures are higher. At higher temperatures the transfer film becomes liquid like, which may be inferred from the 

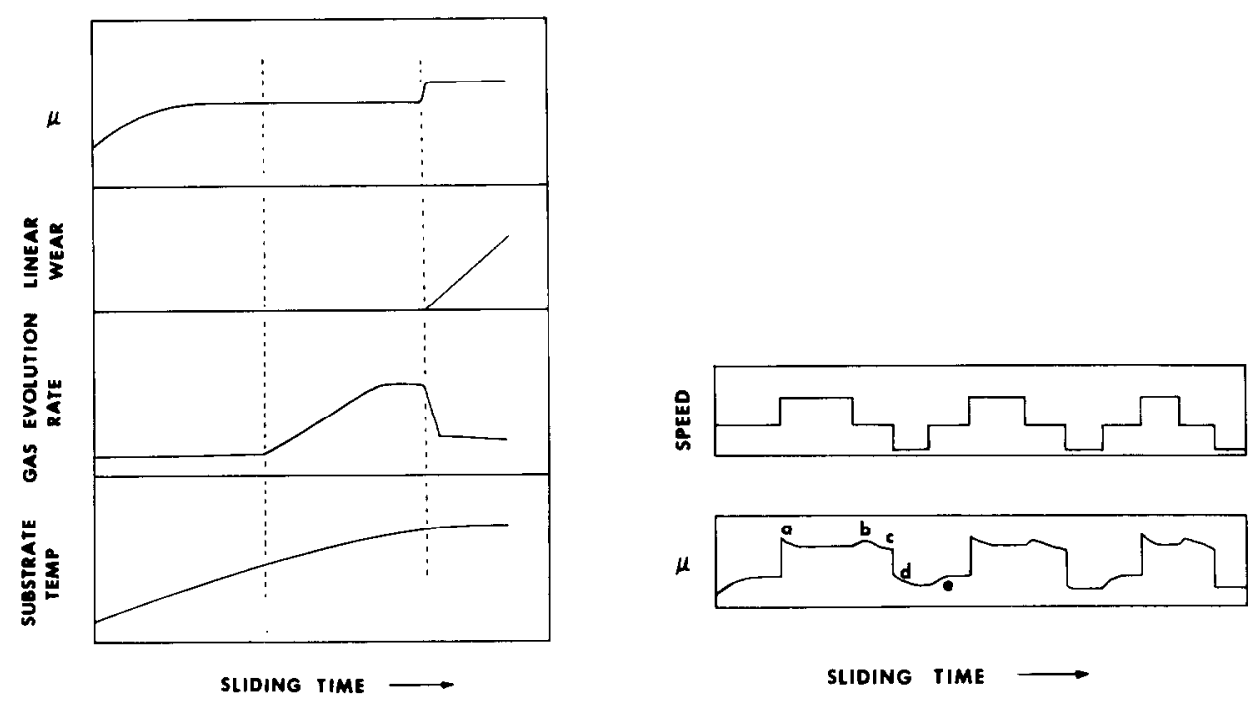

Fig. 2. Schematic data for polymer sliding continuously on quartz and stainless steel.

Fig. 3. Schematic illustration of speed cycle and corresponding data of the coefficient of friction for nylon 66 sliding at $3 \mathrm{~cm} \mathrm{~s}^{-1}, 20 \mathrm{~cm} \mathrm{~s}^{-1}$ and $40 \mathrm{~cm} \mathrm{~s}^{-1}$ under a load of $222 \mathrm{~N}$ $(50 \mathrm{lbf})$ on pins of $6.3 \mathrm{~mm}(1 / 4 \mathrm{in})$ diameter.

rate of gas evolution which always occurs at temperatures in the sliding region above the melting point of the crystalline phase of the polymer. When the latter temperature is reached the viscosity of the amorphous phase of the polymer is in the range of $1 \mathrm{kPa} \mathrm{s}\left(10^{4} \mathrm{P}\right)$ or less.

An interesting observation during the tests on the stainless steel counterface is that with all of the polymers except the polyethylenes $F e$ and $\mathrm{Cr}$ were found attached to the polymer at the end of tests that were stopped before severe wear occurred; however, less was found attached to nylon 11 than to the other polymers. In tests with $222 \mathrm{~N}(50 \mathrm{lbf})$ of load per pin and a value of $\mu=0.5$, with a cross-sectional area of $31.7 \mu \mathrm{m}^{2}\left(0.05 \mathrm{in}^{2}\right)$, the average shear stress at sliding surface is about $3.45 \mathrm{MPa}\left(500 \mathrm{lbf}^{-2}\right)$. This may be compared with the shear strength (at room temperature) shown for the polymers in Table 2. Little can be inferred from this observation since the actual shear strength of the polymer at the temperature of operation is not known. However, the observations indicate that a transfer film is not laid down by successive and simple shear from the polymeric slider. Rather, there is a considerable turbulence or rolling of polymer within the transfer film, at least in the early solid state of the transfer film.

A final test sequence is reported which shows the dual nature of the transfer film. In this test nylon 66 slid against abrasive finished quartz at three speeds, $0.03 \mathrm{~m} \mathrm{~s}^{-1}\left(3 \mathrm{~cm} \mathrm{~s}^{-1}\right), 0.2 \mathrm{~m} \mathrm{~s}^{-1}\left(20 \mathrm{~cm} \mathrm{~s}^{-1}\right)$ and $0.4 \mathrm{~m} \mathrm{~s}^{-1}$ $\left(40 \mathrm{~cm} \mathrm{~s}^{-1}\right)$, with a load of $222 \mathrm{~N}(50 \mathrm{lbf})$. Figure 3 shows schematically the sliding speed cycle and also shows smoothed data for the values of $\mu$ for the 
tests. The high speed always produces gases which usually accompany viscous shear of the transfer film. The low speed produces no gas.

At the beginning of the test, at a speed of $0.2 \mathrm{~m} \mathrm{~s}^{-1}\left(20 \mathrm{~cm} \mathrm{~s}^{-1}\right)$, a transfer film builds up in the conventional manner and it is relatively discontinuous and hard. When the speed increases the value of $\mu$ increases, which is characteristic of the solid state film. However, at a in Fig. 3 the transfer film changes character and $\mu$ decreases. When speed is decreased, $\mu$ increases because the transfer film cools, but then $\mu$ decreases, probably because the transfer film solidifies. Before the value of $\mu$ settles to its original value, the speed in these tests is decreased to $0.03 \mathrm{~m} \mathrm{~s}^{-1}$. The value of $\mu$ decreases gradually, probably because the transfer film cools and fragments. When the speed is again increased the value of $\mu$ increases gradually again to the previous value.

\section{Discussion}

When sliding begins some particles of polymer are torn from the surface of the polymer, leaving pockmarks. The tearing is done by local shear stresses and by softening of regions of the polymer surface by heating. The disposition of the particles removed is now the most important event. If some polymer becomes attached to the substrate such that shearing in the polymer seldom dislodges polymer attached to the substrate, then a transfer film is beginning to form. This condition seems to apply to abrasive finished surfaces using the polymers listed in this paper. More particles continue to be torn from the polymer and most of these particles adhere to the previously formed film.

In some materials some of the particles may become detached, resulting in mild wear. Where few particles are retained there is severe wear. This occurred when sliding several polymers on a polished quartz surface.

As rubbing continues in systems that form transfer films, particles continue to be torn from the polymer and add to the thickness and coverage of the sliding track. During this stage the value of $\mu$ increases to approach a particular maximum value. At some point the film thickness ceases to increase. At low rubbing severities the film is not continuous, allowing for rolling and turbulence of semi-solid particles under the slider with some loss. In this stage the value of $\mu$ increases with increase in speed. At higher sliding severity the film heats up and the viscosity decreases so that the film behaves more as a viscous liquid. The film becomes continuous. In this state the value of $\mu$ is high because of large contact area and $\mu$ is nearly independent of sliding speed. Wear is usually minimal in this state.

Transfer films build up to a maximum and a constant thickness which is probably characteristic of each rubbing pair. This may be explained as follows. At the beginning of sliding the highest temperature and the lowest shear strength is at the polymer-countersurface interface. As particles of polymer become attached to the countersurface that end of the particle 
farthest removed from the countersurface is at the highest temperature and it shears most readily in a narrow shear band. As the film increases in thickness the shear occurs over a thicker shear band and the temperature in the outer layers of transfer film decreases. Thus the tearing of new particles from the polymer is discouraged and eventually ceases. The inner strata or sandwich of transfer film is the highest temperature region in the system. At high severity of rubbing it exceeds $50{ }^{\circ} \mathrm{C}$ above the melting point of the crystalline phase of the polymer as seen by the rate of gas evolution from the transfer film.

The existence of a stable and uniform transfer film thickness brings up the interesting problem of the flow pattern of material "under" the slider. In the case of the viscous flow at high sliding severity the flow cannot be laminar. The highest temperature in the film is probably near the center of the thickness, and at that point the viscosity should be the lowest and the shear gradient would be the largest. This material may flow to the surface at the rear of the slider, which may be the site of gas evolution. In any case the evolution of gases results from heating and not from mechanical shear.

\section{Conclusions}

The following findings are reported.

(1) Severe wear without a transfer film is not due to melting but rather to tearing out of polymer particles which have been softened owing to heating. Severe wear following the formation of a transfer film begins with the agglomeration of the transfer film into loosely attached spheres.

(2) The region of highest temperature in a sliding system with a transfer film is near the mid-section of the transfer film.

(3) In some (perhaps most) systems some surface roughness is required to establish a transfer film.

(4) When a transfer film is formed, severe wear is postponed to a $50^{\circ} \mathrm{C}$ higher temperature than in the system without the transfer film. When a transfer film is formed the wear rate is lower at high severity of sliding than at low severity. At the lower severity the film is composed of semi-solid particles and the value of $\mu$ increases with increasing sliding speed (and vice versa). At higher sliding severity the film is continuous and composed of viscous liquid. The value of $\mu$ is high and nearly independent of sliding speed.

It is obvious from the above results that there are many options available in the coefficient of friction and wear rates of polymers. Simple change in the generic family of polymers assures very little in achieving a design goal. Surface finish of the counterface, sequences of operating conditions and thermal properties of system materials are also important. Doubtless slider geometry and gaseous environment will also emerge as necessary considerations in designing for wear resistance. 


\section{Acknowledgment}

This work was sponsored by the U.S. Army Research Office, North Carolina (Coordinator, Dr. E. A. Saibel).

\section{References}

1 J. M. Challen and D. Dowson, The calculation of interfacial temperatures in the Leeds pin-on-disc machine, Proc. 3rd Leeds-Lyon Symp. on Tribology, Leeds, September 7 10, 1976, Mechanical Engineering Publications, P.O. Box 23, Bury St. Edmunds, Suffolk IP32 6BW, Gt. Britain, to be published.

2 J. K. Lancaster, Dry bearings: a survey of materials and factors affecting their performance, Tribology, 6 (1973) $219-251$.

3 S. H. Rhee and K. C. Ludema, Transfer films and severe wear of polymers, Proc. 3rd Leeds-Lyon Symp. on Tribology, Leeds, September 7 - 10, 1976, Mechanical Engineering Publications, P.O. Box 23, Bury St. Edmunds, Suffolk IP32 6BW, Gt. Britain, to be published.

4 J. F. Archard, The temperature of rubbing surfaces, Wear, 2 (1958/59) $438-455$.

5 Modern Plastics Encyclopaedia, Vol. 52, No. 10A, McGraw-Hill, New York, 1975 1976. 